Document downloaded from:

http://hdl.handle.net/10251/87336

This paper must be cited as:

Betoret Valls, ME.; Calabuig Jimenez, L.; Patrignani, F.; Lanciotti, R.; Dalla Rosa, M. (2017). Effect of high pressure processing and trehalose addition on functional properties of mandarin juice enriched with probiotic microorganisms. Food Science and Technology. 85:418-422. doi:10.1016/j.Iwt.2016.10.036.

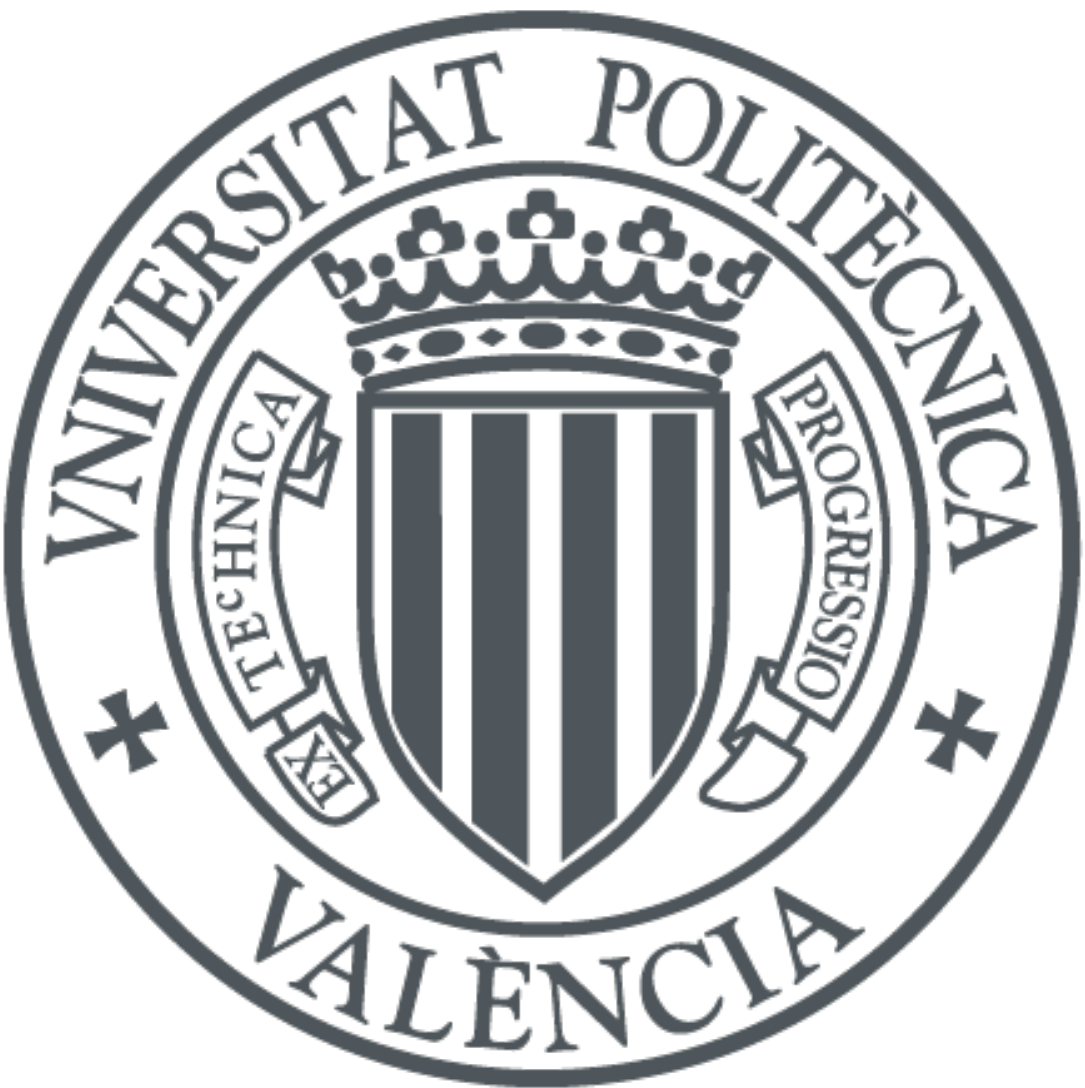

The final publication is available at

http://doi.org/10.1016/j.lwt.2016.10.036

Copyright Elsevier

Additional Information 


\title{
Effect of high pressure processing and trehalose addition on functional properties of mandarin juice enriched with probiotic microorganisms.
}

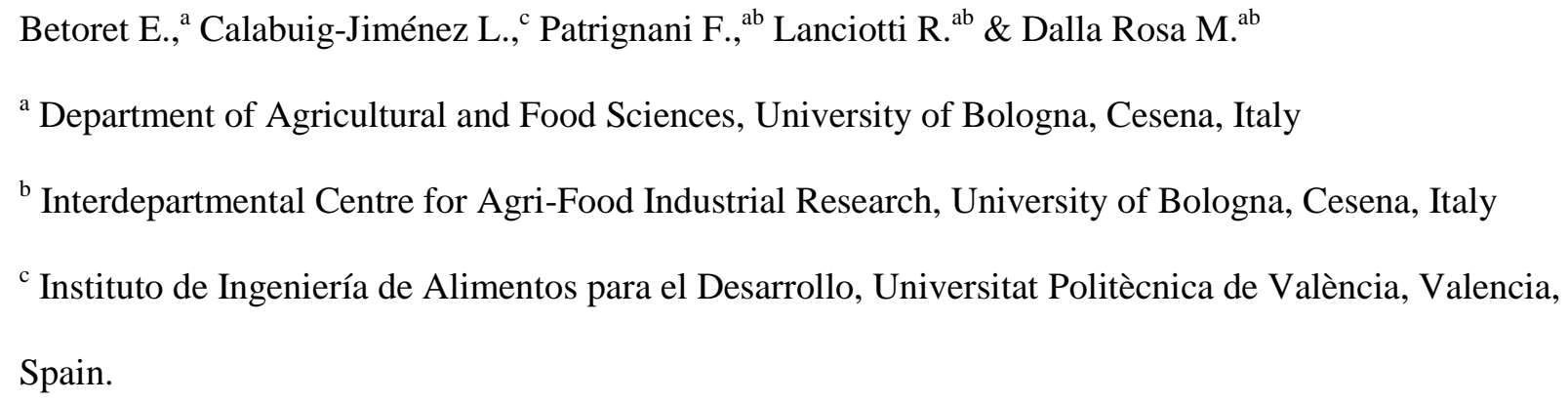

Key words: functional foods, probiotic, homogenization, cell hydrophobicity.

\begin{abstract}
This work aimed to determine the effect of homogenization pressures and addition of trehalose on the functional properties of mandarin juice enriched with Lactobacillus salivarius spp. salivarius. Physicochemical and structural properties of mandarin juice were evaluated and related with quantity and stability of probiotic microorganism as well as with its hydrophobicity. Both food matrix and processing, affected functional properties of L. salivarius spp. salivarius. Homogenization pressures and trehalose addition affected quantity and stability of probiotic microorganisms during storage. $20 \mathrm{MPa}$ and $20 \mathrm{MPa}$ with $100 \mathrm{~g} / \mathrm{kg}$ of trehalose allowed obtaining $10^{6}$ colony forming units $(\mathrm{CFU}) / \mathrm{ml}$ mandarin juice after ten storage days. In MRS growth, cell hydrophobicity increased with homogenization pressures, with values in range $67-98 \%$. Highest cell hydrophobicity was obtained in samples homogenized at $100 \mathrm{MPa}$. Under stress growth conditions, cell hydrophobicity values were in a range $30-84 \%$. In samples no homogenized, addition of trehalose resulted in an increased values of hydrophobicity, with highest levels in those samples with $100 \mathrm{~g} / \mathrm{kg}$ of trehalose addition.
\end{abstract}




\section{Introduction}

Sustainable food production stands at the intersection of several growing needs. Firstly, the needs of consumers for improved food security and safety, as well as healthy needs. Secondly, the quest for economic sustainability of food production, based on cost reduction and increased product differentiation. Third, the growing concern for reversing the over exploitation of natural resources, waste generation, and the contribution to climate change (Fava et al., 2013).

Functional foods can help to prevent or improve some diseases thus contributing directly to the public health and global sustainability. Specifically, probiotic foods can help to prevent or improve the treatment of digestive system diseases and can suppose an alternative strategy to fight antibiotic excessive uses which produce antibiotic resistances and result in a high cost for the Health European System, waste generation and effluent contamination (Betoret et al., 2016). In the development of a probiotic functional food, it is necessary to consider the effect of processing operations on the final product. Foods are mostly complex mixtures of macro and micro components organized in a structure that can trap active compounds, modulating their release or inhibiting their activity (Betoret, Betoret, Rocculi \& Dalla Rosa, 2015). Food matrix, in its raw state or transformed during processing, can have a significant effect on the functionality of bioactive compounds. To choose an appropriate food matrix and technological process, as the key step for the success of a specific functional food, it is necessary to understand the establishment of some interactions between bioactive compounds, cellular structures and technological ingredients that contributing to a "barrier" formation can help to maintain the integrity of bioactive compounds preventing the action of some deterioration factors during processing or storage and ensuring the active compound gaining access to the functional target site in the organism. Structure - property process relationships approach can help developing probiotic functional foods allowing detecting strengths and weaknesses of the system in order to generate technologically feasible strategies that contribute to the success of a functional food (Betoret, Betoret, Rocculi \& Dalla Rosa, 2015). 
The objective of this research was to determine the effect of homogenization pressures and addition of trehalose on the functional properties of mandarin juice enriched with Lactobacillus salivarius spp. salivarius, a probiotic microorganism with potential effect against Helicobacter pylori infection.

\section{Material and methods}

\subsection{Sample preparation}

Ortanique fruit, a hybrid of tangerine and sweet orange (Citrus sinensis x Citrus reticulata) was provided by Rural S. Vicent Ferrer cooperative located in Benaguacil (Valencia), Spain. The preparation of the juices was carried out according to the patent WO/2007/042593 titled "Method of obtaining refrigerated pasteurized citrus juices" (Izquierdo, Carbonell, Navarro \& Sendra, 2007). The fruits were washed by immersing them in tap water, drained, and squeezed in an extractor (“GAM” MOD.SPA 1400 rpm, Cesena, Italy). Raw juice was centrifuged at 3645 x g during 5 min at $4{ }^{\circ} \mathrm{C}$ (Beckman Coulter AvantiTM J-25, California, United States), pasteurized at $63{ }^{\circ} \mathrm{C}$ for $15 \mathrm{~s}$ (Roboqbo Qb8-3, Bologna, Italy), collected in sterile jars, and quickly frozen at $-18{ }^{\circ} \mathrm{C}$ until analyzed.

\subsection{Mandarin juices with $L$. salivarius spp. salivarius}

To obtain mandarin probiotic juices, $2 \mathrm{ml} / \mathrm{l}$ of de Man, Rogosa \& Sharpe (MRS) Broth (VWR, Milan, Italy) with $9 \log$ colony forming units (CFU)/ml L. salivarius spp. salivarius CECT 4063 (Spanish Type Culture Collection, Valencia, Spain) were transferred to mandarin juices following the procedure described by Betoret et al., 2012. After incubation for $24 \mathrm{~h}$ at $37^{\circ} \mathrm{C}$, the juices were homogenized with a Panda Plus pilot homogenizer (GEA Niro Soavi Panda PLUS, Parma, Italy) at 0, 20 and $100 \mathrm{MPa}$. In juice samples with trehalose (Cargill, Milan, Italy), an amount of 100 and $300 \mathrm{~g} / \mathrm{kg}$ was added before homogenization and incubation steps. 


\subsection{Physicochemical characterization}

Total soluble solids were measured as ${ }^{\circ}$ Brix with a digital refractometer (Pal-1; Atago Co., Ltd., Tokyo, Japan). Total titratable acidity was assessed by titration with $0.1 \mathrm{~mol} / \mathrm{l} \mathrm{NaOH}$ (Sigma Aldrich, Milan, Italy) and expressed as the percentage of citric acid. A potentiometer was used to measure $\mathrm{pH}$ (micropH Crison GLP21, Barcelona, Spain). The viscosity was determined by using a portable viscometer (Hydramotion Viscolite 700, York, UK). The values provided are the average of three replicates.

\subsection{Suspended pulp and transmittance}

Suspended pulp was evaluated by sample centrifugation at $365 \mathrm{x}$ g during 10 minutes at $27^{\circ} \mathrm{C}$ (Amador, 2005). The supernatant was collected and evaluated its transmittance at $650 \mathrm{~nm}$ in spectrophotometer (Shimadzu UV-1601, Kyoto, Japan). The values provided are the average of six replicates.

\subsection{Characterization of $L$. salivarius spp. salivarius}

Antagonist activity of L. salivarius spp. salivarius CECT 4063 was evaluated using the methodology described by Siroli et al., 2015. Concretely, $0.5 \mathrm{ml}$ of specific pathogen was inoculated in $10 \mathrm{ml}$ of Brain Heart Infusion (BHI) soft agar (VWR, Milan, Italy) and transferred to the L. salivarius spp. salivarius petri dish. The antagonist activity was evaluated by the inhibition area created by the probiotic microorganism after incubation at $37^{\circ} \mathrm{C}$ for $24 \mathrm{~h}$ against pathogens associated with toxic infections or responsible of food degradation (Table 1). The target strain were chosen according to the literature Siroli et al., 2015 and Pisano et al., 2011. The values provided are the average of three replicates.

Bacteriocin production was evaluated by the inhibition area created by the supernatant after centrifugation at $13000 \mathrm{x} \mathrm{g}$ during $3 \mathrm{~min}$ at $4{ }^{\circ} \mathrm{C}$ (Beckman Coulter AvantiTM J-25, California, United States) of L. salivarius spp. salivarius CECT 4063 boiled and neutralized, boiled but non- 
neutralized, filtered and non-neutralized against the food pathogens presented in Table 1. The values provided are the average of three replicates.

\subsection{Microorganism counting}

Juices homogenized at $0,20,100 \mathrm{MPa}$ with 0,100 and $300 \mathrm{~g} / \mathrm{kg}$ of trehalose content, $L$. salivarius spp. salivarius CECT 4063 were stored during 0,1,2, 3, 7, 10 days at $4{ }^{\circ} \mathrm{C}$. Each day, a juice sample was taken and the number of probiotic microorganisms were counted on double layer MRS agar (VWR, Milan, Italy) following incubation for $24 \mathrm{~h}$ at $37^{\circ} \mathrm{C}$. The values provided are the average of three replicates.

\subsection{Hydrophobicity}

L. salivarius spp. salivarius CECT 4063 hydrophobicity has been calculated following the methodology proposed by Vinderola \& Reinheimer (2003) both in MRS Broth and in mandarin juices homogenized at 0,20,100 MPa with 0,100 and $300 \mathrm{~g} / \mathrm{kg}$ of trehalose content. Methodology was optimized to eliminate interferences in the measurement without affecting probiotic microorganism growth. The values provided are the average of six replicates.

\subsection{Statistical analysis}

A multi factorial ANOVA was carried out to determine the significant effect, with $95 \%$ confidence level, of the process variables with the software STATISTICA 10.

\section{Results and discussion}

\subsection{Characterization of L. salivarius spp. salivarius}

The strain L. salivarius spp. salivarius CECT 4063 was chosen due to its demonstrated activity against Helicobacter pylori infection and because of the results obtained previously (Betoret $e t$ al., 
2012). To characterize the strain, both antagonist activity and bacteriocin production were evaluated.

Antagonist activity of $L$. salivarius spp. salivarius was evaluated against the most common pathogens responsible of food toxic infections or food degradation (Table 1). L. salivarius spp. salivarius showed a positive effect against all food pathogens. Antagonist activity was always high with 6-10 $\mathrm{mm}$ or $>10 \mathrm{~mm}$ inhibition halo for most of pathogens with low levels for L. plantarum, E. faecalis and $S$. enteritidis in which the inhibition halo was 1-6 mm. In order to see if antagonist activity was a result of bacteriocin production, this one was evaluated. No inhibitory activity was detected in the cell supernatant boiled and neutralized, boiled and not neutralized, filtered and neutralized.

3.2 Mandarin juice with L. salivarius spp. salivarius, physicochemical and structural characterization

Mandarin juices homogenized at 0,20 and $100 \mathrm{MPa}$ with $0,100,300 \mathrm{~g} / \mathrm{kg}$ of trehalose were characterized by measuring brix, $\mathrm{pH}$, and acidity (Table 2). Trehalose addition had a significant effect $(\mathrm{p} \leq 0.05)$ on brix, $\mathrm{pH}$ and acidity values obtained. Density and viscosity in mandarin juice homogenized at $0,20,100 \mathrm{MPa}$ and with trehalose addition in $0,100,300 \mathrm{~g} / \mathrm{kg}$ were determined (Table 2). Trehalose addition had a significant effect $(\mathrm{p} \leq 0.05)$ on both density and viscosity measurements. It was possible to observe an increase of both parameters with trehalose addition.

Fruit juices suspension contains cellular organelles and membranes, oil droplets, chromoplasts, fragments of cellular wall such as pectin, cellulose and hemicellulose, and functional compounds (Baker \& Cameron, 1999). As observed in previous studies, homogenization operation associated to the juices production can have influence on the stability of suspended pulp and thus the functional compounds present in the cloud (Betoret, Betoret, Carbonell \& Fito, 2009). Separated pulp by centrifugation at $365 \mathrm{x} \mathrm{g}$ and supernatant transmittance were measured in mandarin juice with 
probiotic microorganism homogenized at $0,20,100 \mathrm{MPa}$ with $0,100,300 \mathrm{~g} / \mathrm{kg}$ trehalose addition (Table 2). As expected, and according to previous studies (Betoret, Betoret, Carbonell \& Fito, 2009), separated pulp and transmittance levels decreased as homogenization pressures increased. This effect can be explained taking into account that homogenization pressures decrease particle size of pulp compounds transforming the suspended pulp that tends to precipitate into more stable background pulp (Betoret, Betoret, Carbonell \& Fito, 2009) and thus stabilizing cloud particles. In those juices with $100 \mathrm{~g} / \mathrm{kg}$ trehalose addition it was possible to observe a decrease of separated pulp and transmittance values that it was even bigger in juices with $300 \mathrm{~g} / \mathrm{kg}$ trehalose addition. This effect could be due to three main reasons: on one hand, samples with trehalose had less quantity of juice and on the other hand trehalose could interact with cloud compounds stabilizing the suspension and maintaining juice cloudiness. Also trehalose addition leads to increased viscosity and therefore an increased resistance against sedimentation and resistance to movement.

3.3 Mandarin juice with L. salivarius spp. salivarius, quantity and stability of probiotic microorganisms

L. salivarius spp. salivarius growth was determined in juices homogenized at $0,20,100 \mathrm{MPa}$ with $0,100,300 \mathrm{~g} / \mathrm{kg}$ trehalose addition after 1, 2, 3, 7 and 10 storage days (Table 3).

The highest growth of probiotic microorganisms was obtained in juices homogenized at 20 $\mathrm{MPa}$. Trehalose addition in $300 \mathrm{~g} / \mathrm{kg}$ resulted in low levels of microorganism growth, probably due to the osmotic pressure created in the media. However, $100 \mathrm{~g} / \mathrm{kg}$ of trehalose addition did not show significant differences when compared with juices without trehalose. When considering storage days, juices with $300 \mathrm{~g} / \mathrm{kg}$ of trehalose addition presented lower microorganism content that remain stable during ten storage days between 5.5 - $3.5 \log \mathrm{CFU} / \mathrm{ml}$ values. In samples with $100 \mathrm{~g} / \mathrm{kg}$ of trehalose addition, levels of probiotic microorganism remained constant until third storage day, from which they start decreasing. In no homogenized samples, high levels of probiotic 
microorganisms quickly started decreasing with storage days. In samples homogenized at 20 and $100 \mathrm{MPa}$, there was an increase in probiotic microorganism at second storage day, probably due to the nutrients availability favored by the small sizes of cloud particles, decreasing from third storage day in samples homogenized at $100 \mathrm{MPa}$. Samples homogenized at $20 \mathrm{MPa}$ had the highest $L$. salivarius spp. salivarius content, stable until seventh storage day.

It seems that smaller size cloud particles together with sub-lethal homogenization pressures creates an optimal environment for L. salivarius spp. salivarius growth. In the same way, cloud stability created by compounds interaction made possible constant preservation of microorganism until seventh storage day. Addition of trehalose without creating an osmotic stress for the microorganism, reinforced juice cloud stability and maintained high microorganism levels until the tenth day of storage.

3.4 Functional properties of L. salivarius spp. salivarius. Determination of cell hydrophobicity and effect of processing technology

In probiotic microorganisms, cellular hydrophobicity has been related with the strain capacity to adhere and interact with intestine wall (Basson, Craig \& Zhang, 2007; Burns et al., 2008). Hydrophobic strains have been described as more cellular and tissue invasive, being able to adhere to the intestine wall thus making possible a successive colonization. Surface hydrophobicity in $L$. salivarius spp. salivarius cells was calculated in MRS Broth medium homogenized at 0, 20, 100 MPa with 0, 100, $300 \mathrm{~g} / \mathrm{kg}$ of trehalose addition (Table 4).

Cell hydrophobicity of L. salivarius spp. salivarius in MRS Broth showed high results in all samples, with values in range $67-98 \%$. Cell hydrophobicity increased with homogenization pressures. Highest cell hydrophobicity was obtained in samples homogenized at $100 \mathrm{MPa}$. As observed in previous studies (Patrignani et al., 2009), sub-lethal homogenization pressures can change cellular structure of microorganism facilitating their adhesion to the digestive system. The 
effect of trehalose addition was different depending on levels of homogenization pressures applied. In samples no homogenized, the addition of trehalose increased cell hydrophobicity. However, in homogenized samples, trehalose addition decreased cell hydrophobicity. Specifically, in those samples homogenized at $20 \mathrm{MPa}$, trehalose addition of 100 and $300 \mathrm{~g} / \mathrm{kg}$ resulted in lower hydrophobicity values, while in samples at $100 \mathrm{MPa}$ there were not significant differences between hydrophobicity values calculated in 100 and $300 \mathrm{~g} / \mathrm{kg}$ trehalose addition samples.

Cell hydrophobicity of L. salivarius spp. salivarius incubated in mandarin juices with 0,100 , $300 \mathrm{~g} / \mathrm{kg}$ trehalose addition and then homogenized at 0, 20 and $100 \mathrm{MPa}$ was calculated (Table 5). Both homogenization pressures and trehalose addition had a significant effect $(\mathrm{p} \leq 0.05)$ on cell hydrophobicity. Analyzed samples showed values in a range $30-84 \%$. In samples no homogenized, addition of trehalose resulted in an increased values of hydrophobicity, with higher levels in those samples with $100 \mathrm{~g} / \mathrm{kg}$ of trehalose addition. The tendency of the results was the same in samples homogenized at 20 and $100 \mathrm{MPa}$, with slightly higher values obtained for $100 \mathrm{MPa}$ homogenization pressures. There were not significant differences in hydrophobicity values obtained in samples homogenized and $100 \mathrm{~g} / \mathrm{kg}$ of trehalose addition. However, $300 \mathrm{~g} / \mathrm{kg}$ of trehalose addition resulted in higher levels of cell hydrophobicity.

As explained by Iaconelli et al., (2015) the measurement of bacterial hydrophobicity remains a good indicator to evaluate variation in bacterial surface properties, especially for an identical strain treated with different processes. The hydrophobicity of L. salivarius spp. salivarius incubated in mandarin juices was lower than that obtained in MRS Broth. The change in cell wall hydrophobicity could be a result of bacterial stress to certain culture conditions, such as low $\mathrm{pH}$, high temperature and hyperosmotic stress (Lopez et al., 2000; Remeta et al., 2002). It seems that in those samples with $300 \mathrm{~g} / \mathrm{kg}$ of trehalose addition, slightly higher $\mathrm{pH}$ and created interactions between trehalose, probiotic microorganisms and juices cloud, protected L. salivarius spp. salivarius and decreased its stress suffered during growing. Decreasing cloud particles size by homogenization, although could contribute to suspension stability, seemed not improve their 
hydrophobicity when they were growth in mandarin juices. High values obtained in samples no homogenized with $100 \mathrm{~g} / \mathrm{kg}$ trehalose addition could be only explained taking into account the variability in cloud juice particles. Bigger particle sizes and less reactive points, could change the interactions created in the media, protecting better L. salivarius spp. salivarius from stress conditions. Trehalose is a disaccharide able to interact with various compounds, forming a glassy amorphous matrix around the tertiary structure of the proteins and phospholipids exerting a protective effect on various technological processes (Colaço \& Roser, 1994). There are a lot of studies demonstrating the ability of trehalose to interact with probiotic cell surface and showing its protecting effect during drying processes (Crowe, Carpenter, Crowe, \& Anchordoguy, 1990). However, there is lack of studies in literature that evaluate the effect of trehalose and juices cloud interactions on hydrophobicity changes in probiotic microorganisms. This effect should be further investigated.

In order to avoid the stress suffered by probiotic microorganisms during incubation in mandarin juices that resulted in microorganism cellular surface changes, cell hydrophobicity of $L$. salivarius spp. salivarius incubated in MRS Broth with $0,100,300 \mathrm{~g} / \mathrm{kg}$ of trehalose addition, homogenized at 0,20 and $100 \mathrm{MPa}$ and then transferred to mandarin juices, was calculated (Table 6). All obtained values were in range $40-80 \%$, higher than those obtained with L. salivarius spp. salivarius incubated in mandarin juices and lower than those obtained in MRS Broth. It was possible to eliminate partially the microorganism growth stress created by low $\mathrm{pH}$ in juices that resulted in microorganism cellular surface hydrophobicity changes, and improve the values obtained. In this case, as in MRS Broth results, homogenization pressures and trehalose addition improved cell hydrophobicity.

\section{Conclusions}

Both food matrix and processing affected functional properties of L. salivarius spp. salivarius. In an optimal growth media, both homogenization pressures and trehalose addition improved cell 
hydrophobicity. Under stress growth conditions, trehalose addition improved cell hydrophobicity and influenced the effects promoted by homogenization pressures. It is necessary to further study trehalose interactions with juices cloud compounds together with microorganism cell surface to understand the mechanisms of action.

\section{Acknowledgements}

This research was supported by a Marie Curie Intra European Fellowship within the 7th European Community Framework Programme. Authors also acknowledge the Universitat Politècnica de València FPI 2014 programme.

\section{References}

Amador, J.R. (2005). Laboratory manual. Procedures for analysis of citrus products. (4th ed.). Florida, USA, FMC Food Tech Inc. (49-50)

Baker, R.A., \& Cameron, R.G. (1999). Clouds of citrus juices and juice drinks. Food Technology, 53, 64-69.

Basson, M.D., Craig, D.H., \& Zhang, J. (2007). Cytoskeletal signaling by way of $\alpha$-actinin-1 mediates ERK1/2 activation by repetitive deformation in human Caco2 intestinal epithelial cells. The American Journal of Surgery, 194(5), 618-622.

Betoret, E., Betoret, N., Carbonell, J.V., \& Fito, P. (2009). Effects of pressure homogenization on particle size and the functional properties of citrus juices. Journal of Food Engineering, 92(1), $18-23$.

Betoret, E., Betoret, N., Arilla, A., Bennár, M., Barrera, C., Codoñer, P., \& Fito, P. (2012). No invasive methodology to produce a probiotic low humid apple snack with potential effect against Helicobacter pylori. Journal of Food Engineering, 110(2), 289-293. 
Betoret, E., Betoret, N., Rocculi, P., \& Dalla Rosa, M. (2015). Strategies to improve food functionality: Structure e property relationships on high pressures homogenization, vacuum impregnation and drying technologies. Trends in Food Science \& Technology, 46(1), 1-12.

Betoret, E., Calabuig-Jiménez, L., Betoret, N., Barrera, C., Seguí, L., \& Fito, P. (2016). Sustainable innovation in food science and engineering, in: Implementation of Innovation in Food Industry, Elsevier, Amsterdam, The Netherlands, 149-165.

Burns, P., Patrignani, F., Serrazanetti, D., Vinderola, G.C., Reinheimer, J.A., Lanciotti, R., \& Guerzoni, M.E. (2008). Probiotic Crescenza cheese containing Lactobacillus casei and Lactobacillus acidophilus manufactured with high-pressure homogenized milk. Journal of Dairy Science, 91(2), 500-512.

Colaço, C.A.L.S., \& Roser, B. (1994). Trehalose, a multifunctional additive for food preservation. In Food packaging and preservation (pp. 123-140). Springer US

Crowe, J.H., Carpenter, J.F., Crowe, L.M., \& Anchordoguy, T.J. (1990). Are freezing and dehydration similar stress vectors? A comparison of modes of interaction of stabilizing solutes with biomolecules. Cryobiology, 27(3), 219-231.

Fava, F., Zanaroli, G., Vannini, L., Guerzoni, E., Bordoni, A., Viaggi, D., ... Brendle, H.G. (2013). New advances in the integrated management of food processing by-products in Europe: sustainable explotation of fruit and cereal processing by-products with the production of new food products (NAMASTE EU). New Biotechnology, 30(6), 647-655.

Iaconelli, C., Lemetais, G., Kechaou, N., Chain, F., Bermúdez-Humarán, L.G., Langella, P., ... Beney, L. (2015) Drying process strongly affects probiotics viability and functionalities. Journal of Biotechnology, 214, 17-26.

Izquierdo, L., Carbonell, J.V., Navarro, J.L., Sendra, J.M., 2007. Method of Obtaining Refrigerated Pasteurized Citrus Juices. Patent WO/2007/042593. Consejo Superior de Investigaciones Científicas, Spain. 
Lopez, C.S., Heras, H., Garda, H., Ruzal, S., Sanchez-Rivas, C., \& Rivas, E. (2000). Biochemical and biophysical studies of Bacillus subtilis envelopes under hyperosmotic stress. International Journal of Food Microbiology. 55(1), 137-142.

Patrignani, F., Capra, M.L., Del Luján Quiberoni, A., Reinheimer, J.A., Lanciotti, R., \& Guerzoni, M.E. (2009). Effect of high pressure homogenization on lactic acid bacteria phages and probiotic bacteria phages. International Dairy Journal, 19(5), 336-341.

Pisano, B., Patrignani, F., Cosentino, S., Guerzoni, M.E., Franz, C.M.A.P., \& Holzapfel W.H. (2011). Diversity and functional properties of Lactobacillus plantarum-group strains isolated from Italian cheese products. Dairy Science \& Technology, 91, 65-76.

Remeta, D.P., Krumbiegel, M., Minetti, C.A.S.A., Puri, A., Ginsburg, A., \& Blumenthal, R. (2002). Acid-induced changes in thermal stability and fusion activity of influenza hemagglutinin. Biochemistry, 41(6), 2044-2054.

Siroli, L., Patrignani, F., Serrazanetti, D.I., Tabanelli, G., Montanari, C., Gardini, F., \& Lanciotti, R. (2015). Lactic acid bacteria and natural antimicrobials to improve the safety and shelf-life of minimally processed sliced apples and lamb's lettuce. Food Microbiology, 47, 74-84

Vinderola, C.G., \& Reinheimer, J.A. (2003). Lactic acid starter and probiotic bacteria: a comparative "in vitro" study of probiotic characteristics and biological barrier resistance. Food Research International, 36(9), 895-904. 
Table 1. Antagonist activity of $L$. salivarius spp. salivarius against most common food pathogenic and spoilage bacteria (Siroli et al., 2015; Pisano et al., 2011). The values provided are the average of three replicates.

\begin{tabular}{llc}
\hline & & $\begin{array}{c}\text { L. salivarius spp. salivarius } \\
\text { CECT 4063 inhibition }\end{array}$ \\
\hline L. monocytogenes & ATCC 13932 & ++++ \\
L. monocytogenes & SCOTT A & ++++ \\
L. innocua & DSM 20649 & ++++ \\
L. plantarum & V7B3 & + \\
B. cereus & ATCC11966 & +++ \\
S. aureus & DSM 20231 & +++ \\
E. faecalis & ATCC29212 & ++ \\
E. faecalis & EF37 & +++ \\
E. coli & DSM 18039 & ++++ \\
E. coli & 555 & ++++ \\
S. enteritidis & E5 & ++ \\
\hline
\end{tabular}

Legend: - (no inhibition); + (inhibition 1-3 mm); ++ (inhibition 3-6 mm); +++ (inhibition 6-10 $\mathrm{mm}) ;++++($ inhibition $>10 \mathrm{~mm})$. 
Table 2. Physicochemical characterization of mandarin juices with L. salivarius spp. salivarius. Values expressed as mean \pm standard deviation.

The values provided are the average of three replicates. In the case of separated pulp and transmittance the values provided are the average of six replicates.

\begin{tabular}{|c|c|c|c|c|c|c|c|c|}
\hline $\begin{array}{l}\text { Pressure } \\
\text { MPa }\end{array}$ & $\begin{array}{c}\text { Trehalose } \\
(\mathrm{g} / \mathrm{kg})\end{array}$ & $\begin{array}{c}{ }^{\mathbf{O} B r i x} \\
\left(\mathrm{~g}_{\text {soluble solids } / \text { gliquid phase }}\right)\end{array}$ & pH & $\begin{array}{c}\text { Acidity } \\
(\mathrm{g} / \mathrm{l})\end{array}$ & $\begin{array}{c}\text { Density } \\
\left(\cdot \mathbf{1 0}^{3}\right)(\mathrm{g} / \mathrm{l})\end{array}$ & $\begin{array}{c}\text { Viscosity } \\
\left(\cdot \mathbf{1 0}^{-3}\right)(\mathbf{P a} \cdot \mathbf{s}) \\
\end{array}$ & $\begin{array}{c}\text { Separated pulp } \\
(\mathrm{ml} / \mathrm{l})\end{array}$ & $\begin{array}{c}\text { Transmittance } \\
(\%)\end{array}$ \\
\hline $\mathbf{0}$ & 0 & $13.53 \pm 0.06$ & $3.87 \pm 0.06$ & $1.59 \pm 0.05$ & $1.06 \pm 0.02^{\mathrm{c}}$ & $1.57 \pm 0.06^{\mathrm{e}}$ & $93.33 \pm 0.06^{\mathrm{ab}}$ & $20.1 \pm 1.2^{\mathrm{a}}$ \\
\hline $\mathbf{0}$ & 100 & $21.40 \pm 0.12$ & $3.97 \pm 0.06$ & $1.37 \pm 0.06$ & $1.09 \pm 0.03^{\mathrm{b}}$ & $2.23 \pm 0.06^{\mathrm{d}}$ & $83.33 \pm 0.06^{c}$ & $17.8 \pm 2.2^{\mathrm{ab}}$ \\
\hline 0 & 300 & $36.70 \pm 0.12$ & $4.30 \pm 0.12$ & $0.90 \pm 0.08$ & $1.17 \pm 0.02^{\mathrm{a}}$ & $6.10 \pm 0.12^{\mathrm{a}}$ & $46.66 \pm 0.06^{\mathrm{d}}$ & $7.5 \pm 1.6^{\mathrm{c}}$ \\
\hline 20 & $\mathbf{0}$ & $13.03 \pm 0.06$ & $3.87 \pm 0.06$ & $1.53 \pm 0.03$ & $1.06 \pm 0.02^{\mathrm{c}}$ & $1.7 \pm 0.2^{\mathrm{e}}$ & $86.66 \pm 0.06^{\mathrm{bc}}$ & $16.6 \pm 1.3^{\mathrm{b}}$ \\
\hline 20 & 100 & $20.70 \pm 0.12$ & $3.93 \pm 0.06$ & $1.39 \pm 0.05$ & $1.09 \pm 0.02^{\mathrm{b}}$ & $2.23 \pm 0.06^{\mathrm{d}}$ & $83.33 \pm 0.12^{c}$ & $7.1 \pm 0.8^{c}$ \\
\hline 20 & 300 & $35.8 \pm 0.2$ & $4.17 \pm 0.06$ & $0.9 \pm 0.2$ & $1.16 \pm 0.04^{\mathrm{a}}$ & $4.7 \pm 0.2^{c}$ & $2.00 \pm 0.02^{\mathrm{e}}$ & $6.7 \pm 0.3^{c}$ \\
\hline 100 & 0 & $13.2 \pm 0.2$ & $3.8 \pm 0.02$ & $1.5 \pm 0.2$ & $1.05 \pm 0.03^{\mathrm{c}}$ & $1.67 \pm 0.06^{\mathrm{e}}$ & $10.00 \pm 0.02^{\mathrm{a}}$ & $9.0 \pm 2.7^{\mathrm{c}}$ \\
\hline 100 & 100 & $20.90 \pm 0.12$ & $3.9 \pm 0.02$ & $1.4 \pm 0.2$ & $1.084 \pm 0.013^{b}$ & $2.2 \pm 0.2^{\mathrm{d}}$ & $8.00 \pm 0.02^{\mathrm{c}}$ & $5.37 \pm 0.08^{\mathrm{d}}$ \\
\hline 100 & 300 & $34.6 \pm 0.4$ & $4.2 \pm 0.02$ & $0.9 \pm 0.2$ & $1.16 \pm 0.02^{\mathrm{a}}$ & $5.0 \pm 0.2^{b}$ & $2.00 \pm 0.02^{\mathrm{e}}$ & $1.8 \pm 0.2^{\mathrm{e}}$ \\
\hline
\end{tabular}

* Values with different superscript letters in a column are significantly different $(\mathrm{p} \leq 0.05)$ 
Table 3. L. salivarius spp. salivarius content in mandarin juices during storage (log $\mathrm{CFU} / \mathrm{ml})$. Values expressed as mean \pm standard deviation. The values provided are the average of three replicates.

\begin{tabular}{ccccccc}
\hline $\begin{array}{c}\text { Pressure } \\
\text { MPa }\end{array}$ & $\begin{array}{c}\text { Trehalose } \\
\mathbf{g} / \mathbf{k g}\end{array}$ & $\mathbf{1}$ & $\mathbf{2}$ & Storage days \\
\hline $\mathbf{0}$ & $\mathbf{0}$ & $8.10 \pm 0.02^{\mathrm{abc}}$ & $7.8 \pm 0.2^{\mathrm{b}}$ & $7.09 \pm 0.06^{\mathrm{bcd}}$ & $5.84 \pm 0.09^{\mathrm{d}}$ & $5.2 \pm 0.2^{\mathrm{d}}$ \\
$\mathbf{0}$ & $\mathbf{1 0 0}$ & $7.7 \pm 0.4^{\mathrm{cd}}$ & $8.54 \pm 0.09^{\mathrm{a}}$ & $7.5 \pm 0.09^{\mathrm{ac}}$ & $7.6 \pm 0.02^{\mathrm{b}}$ & $6.29 \pm 0.02^{\mathrm{b}}$ \\
$\mathbf{0}$ & $\mathbf{3 0 0}$ & $4.7 \pm 0.2^{\mathrm{f}}$ & $4.0 \pm 0.2^{\mathrm{c}}$ & $4.5 \pm 0.02^{\mathrm{e}}$ & $3.5 \pm 0.2^{\mathrm{f}}$ & $3.54 \pm 0.09^{\mathrm{f}}$ \\
$\mathbf{2 0}$ & $\mathbf{0}$ & $8.39 \pm 0.04^{\mathrm{ab}}$ & $8.58 \pm 0.04^{\mathrm{a}}$ & $8.5 \pm 0.9^{\mathrm{a}}$ & $8.45 \pm 0.05^{\mathrm{a}}$ & $6.77 \pm 0.12^{\mathrm{a}}$ \\
$\mathbf{2 0}$ & $\mathbf{1 0 0}$ & $8.19 \pm 0.02^{\mathrm{b}}$ & $8.22 \pm 0.12^{\mathrm{ab}}$ & $8.25 \pm 0.12^{\mathrm{ad}}$ & $7.8 \pm 0.3^{\mathrm{b}}$ & $6.8 \pm 0.3^{\mathrm{a}}$ \\
$\mathbf{2 0}$ & $\mathbf{3 0 0}$ & $5.3 \pm 0.2^{\mathrm{e}}$ & $4.3 \pm 0.5^{\mathrm{c}}$ & $4.6 \pm 0.8^{\mathrm{e}}$ & $4.8 \pm 0.2^{\mathrm{e}}$ & $4.98 \pm 0.03^{\mathrm{d}}$ \\
$\mathbf{1 0 0}$ & $\mathbf{0}$ & $7.46 \pm 0.12^{\mathrm{d}}$ & $8.6 \pm 0.2^{\mathrm{a}}$ & $8.24 \pm 0.02^{\mathrm{a}}$ & $7.6 \pm 0.2^{\mathrm{b}}$ & $5.80 \pm 0.14^{\mathrm{c}}$ \\
$\mathbf{1 0 0}$ & $\mathbf{1 0 0}$ & $7.8 \pm 0.2^{\mathrm{bd}}$ & $7.8 \pm 0.02^{\mathrm{b}}$ & $7.8 \pm 0.3^{\mathrm{ab}}$ & $6.81 \pm 0.05^{\mathrm{c}}$ & $5.5 \pm 0.3^{\mathrm{cd}}$ \\
$\mathbf{1 0 0}$ & $\mathbf{3 0 0}$ & $4.7 \pm 0.2^{\mathrm{f}}$ & $4.5 \pm 0.02^{\mathrm{c}}$ & $4.39 \pm 0.12^{\mathrm{e}}$ & $4.7 \pm 0.3^{\mathrm{e}}$ & $4.2 \pm 0.2^{\mathrm{e}}$ \\
\hline
\end{tabular}

$*$ Values with different superscript letters in a column are significantly different $(\mathrm{p} \leq 0.05)$

Table 4. Cell hydrophobicity (\%) of L. salivarius spp. salivarius incubated in MRS Broth. Values expressed as mean \pm standard deviation. The values provided are the average of six replicates

\begin{tabular}{ccc}
\hline $\begin{array}{c}\text { Pressure } \\
\text { MPa }\end{array}$ & $\begin{array}{c}\text { Trehalose } \\
\text { g/kg }\end{array}$ & $\begin{array}{c}\text { Cell hydrophobicity } \\
(\%)\end{array}$ \\
\hline $\mathbf{0}$ & $\mathbf{0}$ & $66.9 \pm 9.6^{\mathrm{gh}}$ \\
$\mathbf{0}$ & $\mathbf{1 0 0}$ & $90.4 \pm 2.7^{\mathrm{ac}}$ \\
$\mathbf{0}$ & $\mathbf{3 0 0}$ & $80.0 \pm 11.5^{\mathrm{de}}$ \\
$\mathbf{2 0}$ & $\mathbf{0}$ & $94.3 \pm 0.8^{\mathrm{ab}}$ \\
$\mathbf{2 0}$ & $\mathbf{1 0 0}$ & $84.8 \pm 6.9^{\mathrm{bcd}}$ \\
$\mathbf{2 0}$ & $\mathbf{3 0 0}$ & $73.0 \pm 3.9^{\mathrm{efg}}$ \\
$\mathbf{1 0 0}$ & $\mathbf{0}$ & $98.2 \pm 1.9^{\mathrm{efh}}$ \\
$\mathbf{1 0 0}$ & $\mathbf{1 0 0}$ & $71.9 \pm 12.2^{\mathrm{df}}$ \\
$\mathbf{1 0 0}$ & $\mathbf{3 0 0}$ & $79.40 \pm 1.12^{\mathrm{a}}$ \\
\hline
\end{tabular}

* Values with different superscript letters in a column are significantly different $(\mathrm{p} \leq 0.05)$ 
Table 5. Cell hydrophobicity (\%) of L. salivarius spp. salivarius incubated in mandarin juices. Values expressed as mean \pm standard deviation. The values provided are the average of six replicates

\begin{tabular}{ccc}
\hline $\begin{array}{c}\text { Pressure } \\
\text { MPa }\end{array}$ & $\begin{array}{c}\text { Trehalose } \\
\text { g/kg }\end{array}$ & $\begin{array}{c}\text { Cell hydrophobicity } \\
(\%)\end{array}$ \\
\hline $\mathbf{0}$ & $\mathbf{0}$ & $32.5 \pm 7.9^{\mathrm{ef}}$ \\
$\mathbf{0}$ & $\mathbf{1 0 0}$ & $86.3 \pm 4.6^{\mathrm{a}}$ \\
$\mathbf{0}$ & $\mathbf{3 0 0}$ & $55.2 \pm 4.3^{\mathrm{d}}$ \\
$\mathbf{2 0}$ & $\mathbf{0}$ & $27.3 \pm 1.5^{\mathrm{f}}$ \\
$\mathbf{2 0}$ & $\mathbf{1 0 0}$ & $27.3 \pm 3.5^{\mathrm{f}}$ \\
$\mathbf{2 0}$ & $\mathbf{3 0 0}$ & $63.4 \pm 5.8^{\mathrm{c}}$ \\
$\mathbf{1 0 0}$ & $\mathbf{0}$ & $37.3 \pm 6.2^{\mathrm{e}}$ \\
$\mathbf{1 0 0}$ & $\mathbf{1 0 0}$ & $35.3 \pm 6.2^{\mathrm{e}}$ \\
$\mathbf{1 0 0}$ & $\mathbf{3 0 0}$ & $73.6 \pm 7.3^{\mathrm{b}}$ \\
\hline
\end{tabular}

* Values with different superscript letters in a column are significantly different $(\mathrm{p} \leq 0.05)$

Table 6. Cell hydrophobicity (\%) of L. salivarius spp. salivarius incubated in MRS Broth and transferred to mandarin juices. Values expressed as mean \pm standard deviation. The values provided are the average of six replicates

\begin{tabular}{ccc}
\hline $\begin{array}{c}\text { Pressure } \\
\text { MPa }\end{array}$ & $\begin{array}{c}\text { Trehalose } \\
\text { g/kg }\end{array}$ & $\begin{array}{c}\text { Cell hydrophobicity } \\
(\boldsymbol{\%})\end{array}$ \\
\hline $\mathbf{0}$ & $\mathbf{0}$ & $40.1 \pm 6.9^{\mathrm{c}}$ \\
$\mathbf{0}$ & $\mathbf{1 0 0}$ & $72.1 \pm 9.2^{\mathrm{a}}$ \\
$\mathbf{0}$ & $\mathbf{3 0 0}$ & $55.3 \pm 3.4^{\mathrm{b}}$ \\
$\mathbf{2 0}$ & $\mathbf{0}$ & $42.9 \pm 3.9^{\mathrm{c}}$ \\
$\mathbf{2 0}$ & $\mathbf{1 0 0}$ & $72.1 \pm 0.3^{\mathrm{a}}$ \\
$\mathbf{2 0}$ & $\mathbf{3 0 0}$ & $77.0 \pm 9.2^{\mathrm{a}}$ \\
$\mathbf{1 0 0}$ & $\mathbf{0}$ & $57.2 \pm 11.8^{\mathrm{ab}}$ \\
$\mathbf{1 0 0}$ & $\mathbf{1 0 0}$ & $52.9 \pm 7.6^{\mathrm{b}}$ \\
$\mathbf{1 0 0}$ & $\mathbf{3 0 0}$ & $55.9 \pm 8.2^{\mathrm{b}}$ \\
\hline
\end{tabular}

* Values with different superscript letters in a column are significantly different $(\mathrm{p} \leq 0.05)$ 